\title{
COMENTARIO A PLAUT. CAS. 931-932
}

Francisco Garcia Jurado

0. El conocimiento del sistema preverbial latino, aun en sus aspectos básicos, resulta un instrumento precioso para la correcta comprensión de los textos, donde a menudo los preverbios llegan a tener una importancia de primer orden. Este es el caso de unos versos de la comedia plautina Casina (931-932), en los que la sabia utilización de un conjunto de preverbios proporciona al lector una imagen espacial precisa de lo que allí se cuenta. Sabemos que esta comedia es una de las más bufonescas del corpus plautino', pues nuestro autor no duda en utilizar unos recursos tremendamente grotescos que puedan poner en ridículo tanto a Lisídamo, el sempiterno anciano, como a su colono, Olimpión. Lisidamo desea a la misma joven sierva que su hijo, por lo que no duda en enviar a éste lejos de casa. Para disimular ante su mujer, pretende casar a la sierva con su colono, quien accede gustoso, en la esperanza de poder obtener partido de la misma joven. Sin embargo, uno y otro caerán en una ridícula trampa, pues cuando logran finalmente tener a la novia en sus manos, ésta ha sido sustituida por un siervo, Calino, que habrá de darles su justo merecido. Precisamente, esta situación va a brindar a Plauto la escena más divertida de toda la comedia, en la que Olimpión, una vez que logra huir de las garras de la varonil novia, relata a la mujer de Lisidamo su "affaire» nupcial. Después de algunos comentarios acerca de las especiales características fisicas de la novia y de su inu-

' Así lo comenta A. Ernout en la notice sobre Casina que nos da en su edición: «Mais Plaute n'a vu dans le sujet qu'il a choisi que l'occasion d'écrire une énorme bouffonnerie, joviale et débraillée, où l'outrance même des situations fait oublier l'obcénitén (Plaute, $\mathrm{Co}$ médies, tome II, Paris, 1964, p. 152). 
sitada violencia, Olimpión narra en dos concisos versos la manera en que huye de ella (Cas. 931-932):

Decido de lecto praecipes; subsilit, optundit os mihi.

Inde foras tacitus profugiens exeo hoc ornatu quo uides (...)

En este breve pasaje la comedia alcanza uno de los momentos más precipitados (praecipes), a la vez que la precisión de los preverbios da una perfecta idea del espacio y el recorrido de la acción. Vamos a comentar brevemente cada uno de los preverbios que aparecen en la misma:

1. Tras un texto fragmentario (923-930), donde suponemos el forcejeo de Olimpión con Calino disfrazado, este último comienza a golpear a aquél fieramente. Es entonces cuando Olimpión cae del lecho (decido de lecto). El preverbio de-, así como la preposición correspondiente, presentan un valor sémico-espacial que indica el movimiento ablativo "desde arriba»", opuesto al contenido de sub-, que precisamente indica el contenido adlativo «hacia arriba». Plauto ha sabido concatenar sabiamente ambos contenidos, de manera que resalten la caída de Olimpión, en su deseo de alejarse de Calino (noción ablativa), y la acción adlativa de éste (subsilit), en dirección ascendente contra el improvisado marido ${ }^{3}$, sobre el que cae violentamente:

decido («desde arriba») / subsilit («hacia arriba») ${ }^{4}$

2 Para los valores sémico-espaciales véase B. Garcia Hernández, Semántica Estructural y Lexemática del Verbo, Reus 1980, pp. 123-241.

${ }^{3}$ El carácter adlativo de subsilio puede verse claramente en Lucr. 2, 191 Nec cum subsiliunt ignes ad tecta domorum.

- Las traducciones que hemos revisado son desiguales en su interpretación de este breve pasaje:

- A. Ernout no ha sabido ver el carácter ascendente y adlativo de subsilit, y lo interpreta según uno de los valores secundarios de sub- ("a continuación»):

"Je tombe du lit la tête la première; elle saute après moi.»

- Paul Nixon enfatiza el carácter ascendente de subsilit, lo que la propia lengua inglesa le permite hacer fácilmente: "I fall off the couch head first; up she jumps."

- Pero es, sin duda alguna, Marçal Olivar el que da con la clave del texto, pues la acción de subsilit implica, a su vez, el salto sobre Olimpión:

"Caic del llit, de cap; ella que em salta a sobre."

Podemos encontrar otros modificados de sub- utilizados en contextos similares:

Verg. Aen. 12, 287-288 infrenant alii currus aut corpora saltu subiciunt in equos et strictis ensibus adsunt. 
La clave, en este caso, está en apreciar cómo el plano vertical expresado por de-/sub- refleja el amedrentamiento de Olimpión, a la vez que la ferocidad de Calino, que se monta sobre aquél en una cómica escena donde la novia presenta el comportamiento que se supondría del varón. De- y subtienen aquí sus contenidos sémicos originales 5 .

A su vez, Olimpión nos cuenta que «cae de cabeza» (praecipes). Las anteriores nociones de sub- y de- indican la dirección, mientras que prae- se refiere a la posición, que en este caso es "por delante» ${ }^{6}$. A esta realización de prae- se opone la noción "por detrás», expresada también por sub-, pero con carácter secundario:

\section{Cas. 377 Quis mihi subuenit tergo (...)?}

El hecho de caer con la cabeza "por delante» sitúa la acción de optundit (os mihi). Al descender de la cama, posiblemente de espaldas ${ }^{7}$, Olimpión recibe un puñetazo de Calino en el rostro. El preverbio ob- en optundit expresa también una dirección, al igual que lo hace el par de-/sub-, pero, a diferencia de éstos, la dirección de ob- está ahora determinada por un límite orientado $^{8}$, que se corresponde con el propio rostro de Olimpión, al caer de cabeza. Ob-, en este caso, presenta una noción adlativa de «enfrentamiento" (aduersus) $^{9}$ :

$$
\text { optundit } \rightarrow
$$

No es dificil encontrar en Plauto situaciones análogas, como es el caso siguiente, dentro de la misma comedia:

Cas. 412 Tempori, postquam oppugnatum est os

«De- y sub- accedieron a indicar, respectivamente, la dirección ablativa (decedo) y la adlativa (succedo) de modo secundario, pues su relación originaria se sitúa en el plano vertical» (B. García Hernández, Semántica..., p. 215).

- B. García Hernández. Semántica..., p. 183.

' Debo agradecer al profesor Garcia Hernández las valiosas ideas que me ha dado a la hora de situar las acciones de una forma precisa.

Para el concepto de límite véase B. Pottier, Systématique des éléments de relation, Paris 1962, pp. 276-291. p. 289

B. Garcia Hernández, Semántica..., p. 172. Para el esquema cf. B. Pottier, Systématique.... 
Toda vez que probablemente tengamos una cómica aliteración entre os y el preverbio ob-, a causa de la cual esta parte de nuestra anatomía se ha convertido en un lugar idóneo para los golpes ${ }^{10}$.

Frente al carácter hostil de optundit, aparece en el verso siguiente un modificado de pro-, cuya noción sémico-espacial "adelante» (porro) también está sujeta a un límite orientado, que en el caso que nos ocupa se corresponde, probablemente, con los puños de Calino, de cuyo alcance pretende huir Olimpión yendo, precisamente, hacia adelante:

$$
\underset{\text { inde }}{\longrightarrow} \rightarrow \text { profugiens" }
$$

De esta manera, si antes era el plano vertical expresado por de-/sub-, ahora es en el plano horizontal, planteado entre ob- y pro-, donde la lucha se sitúa:

$$
\text { optundit } \underset{\text { os }}{\rightarrow} \underset{\text { inde }}{\longrightarrow} \rightarrow \text { profugiens }^{12}
$$

Merece, pues, la pena poner de relieve las direcciones opuestas de optundit y de profugiens respecto a sus respectivos límites orientados, lo que acentúa aún más la furia de la supuesta recién casada y el miedo del marido frustrado (profugus).

Como culminación de la huida, Olimpión logra salir de la estancia (exeo). El preverbio ex-indica, precisamente, la salida del interior de un «limite doble», que en la escena se corresponde con la propia habitación, de la que acaba de salir:

${ }^{10}$ Damos a continuación algunos ejemplos extraídos de las comedias de Plauto donde aparece el juego entre os y ob-:

Poe. 19 neu dissignator praeter os obambulet.

Poe. 1195 an tu eo pulcra uidere... si tibi illi non os oblitumst fuligine?

St. 114 Omnibus os opturent ne quis merito male dicat sibi.

Am. 183 mihi aduenienti os occillet.

As. 586 opprime os: is est.

Mo. 619 iube obicere argentum ob os inpurae beluae.

" B. García Hernández, Semántica..., p. 188; para el esquema cf. B. Pottier, Systématique..., p. 286.

${ }_{12}$ Otro ejemplo basado en la oposición de ob- y pro- es el siguiente pasaje:

Cas. 806 quid si etiam offendam hymenaeum, si qui citius prodeant?

Obsérvese qué útiles son los preverbios con límite orientado para situar la trama dentro de la escena. 


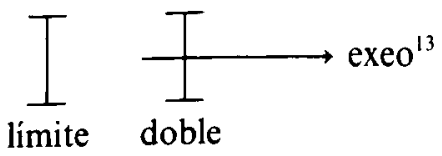

Al preverbio ex-, elativo, se opone el preverbio ilativo in-, que, entre sus valores sémico-espaciales, presenta el de «penetración» e «introducción» en un límite, igualmente doble ${ }^{14}$ :

Cas. 589 Iampol ego huic aliquem in pectus iniciam metum

Por lo tanto, Olimpión termina por salir fuera (foras), y así da fin a su accidentada historia nupcial.

2. Como puede observarse fácilmente, la característica básica de este breve pasaje es la variedad e importancia de los preverbios que en él aparecen. Si los consideramos ahora en conjunto, podemos ver que, con la excepción de prae-, todos ellos son de carácter direccional, lo que justifica el dinamismo del texto. Pero lo que realmente nos da la clave para explicar el pasaje es la diferencia esencial que hay en el tipo de limite al que se refieren las distintas clases de preverbios direccionales que hemos encontrado, pues el límite es determinante a la hora de situar la acción:

$\begin{array}{ll}\text { deido/(subsilit): } & \text { límite simple (de lecto) } \\ \text { optundit/(profugiens): } & \text { límite orientado (os mihi) } \\ \text { exeo/(ineo): } & \text { límite doble (foras) }\end{array}$

Así las cosas, el limite simple al que se refiere el preverbio de- en decido de lecto centra la atención en el alejamiento del lecho y caída al suelo, mientras que en subsilit la acción se dirige hacia Olimpión, para caer sobre él. En optundit es muy importante que el límite tenga una dirección precisa, de manera que el movimiento hostil de choque se produzca; ya se ha especificado previamente que Olimpión cae «de cabeza», por lo que os va a ser ahora el centro de la acción. Olimpión no hace más que seguir la dirección del límite orientado, que son los puños de Calino, de manera que huye

"B. Garcia Hernández, Semántica..., p. 155; para el esquema véase igualmente B. Pottier, Systématique..., p. 280.

14 B. García Hernández, Semántica..., p. 161. 
«hacia adelante» (profugit), en un intento de esquivar los obcecados golpes que su cruel y falsa esposa le propina.

Finalmente, el límite doble que depende del preverbio ex- (exeo) centra nuestra atención en la salida de la estancia y, en definitiva, en el fin de toda la accidentada historia. El carácter lineal de la huida de Olimpión puede resumirse con un gráfico general, donde integramos los distintos valores sémico-espaciales de los preverbios en una secuencia continua, y donde además consideramos los distintos límites propuestos:

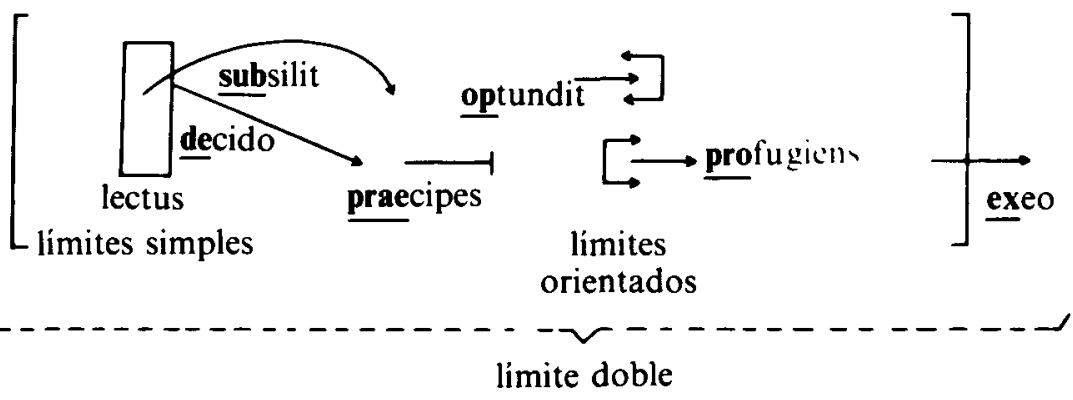

En conclusión, creemos que es un ilustrativo ejemplo de cómo Plauto ha sabido explotar los recursos estilísticos que el rico sistema preverbial latino le brinda, donde los límites a que cada preverbio hace referencia son más que suficientes para encuadrar y representar la acción, como si de una acotación escénica se tratase. 